\title{
Mapping of the CaPP2C35 Gene Involved in the Formation of Light-Green Immature Pepper (Capsicum Annuum L.) Fruits via GWAS and BSA
}

\section{Lang Wu}

China Agricultural University

Haoran Wang

China Agricultural University

Sujun Liu

China Agricultural University

Mengmeng Liu

China Agricultural University

Jinkui Liu

China Agricultural University

\section{Yihao Wang}

China Agricultural University

\section{Liang Sun}

China Agricultural University

Wencai Yang

China Agricultural University

Huolin Shen ( $D$ SHL1606@cau.edu.cn )

China Agricultural University https://orcid.org/0000-0001-9637-045X

\section{Research Article}

Keywords: Pepper, fruit color, gene mapping, chlorophyll

Posted Date: September 22nd, 2021

DOl: https://doi.org/10.21203/rs.3.rs-894733/v1

License: (c) (i) This work is licensed under a Creative Commons Attribution 4.0 International License. Read Full License

Version of Record: A version of this preprint was published at Theoretical and Applied Genetics on November 11th, 2021. See the published version at https://doi.org/10.1007/s00122-021-03987-9. 


\section{Abstract}

In pepper (Capsicum annuum L.), the common colors of immature fruits are yellowish white, milky yellow, green, purple, and purplish black. Some genes related to these colors have been cloned, but only those related to dark green, white, and purple immature fruits; few studies have investigated light-green immature fruits. Here, we performed a genetic study using light-green (17C827) and green (17C658) immature fruits. We found that the light-green color of immature fruits were controlled by a single locusdominant genetic trait compared with the green color of immature fruits. We also performed a genomewide association study and bulked segregant analysis of immature-fruit color and mapped the $L G$ locus to a $35.07 \mathrm{kbp}$ region on chromosome 10. Only one gene, Capana10g001710, was found in this region. A G-A substitution occurred at the $313^{\text {th }}$ base of the Capana $10 \mathrm{~g} 001710$ coding sequence in $17 \mathrm{C} 827$, resulting in the a-helix of its encoded PP2C35 protein to turn into a $\beta$-fold. The expression of Capana10g001710 (termed CaPP2C35) in 17C827 was significantly higher than in 17C658. Silencing of CaPP2C35 in 17C827 resulted in an increase in chlorophyll content in the exocarp and the appearance of green stripes on the surface of the fruit. These results indicate that CaPP2C35 may be involved in the formation of light-green immature fruits by regulating the accumulation of chlorophyll content in the exocarp. Thus, this research lays the foundation for further studies and genetic improvement of immature-fruit color in pepper.

\section{Key Message}

Genome-wide association study, bulked segregant analysis, and genetic analysis delimited the $L G$ locus controlling light-green immature pepper fruits into a $35.07 \mathrm{kbp}$ region on chromosome 10 . A strong candidate gene, CaPP2C35, was identified in this region.

\section{Introduction}

Fruit color is one of the most important traits of pepper (Capsicum annuum L.) appearance, as it is the main reference standard used by consumers for selecting and purchasing peppers (Jang et al. 2020). Thus, research on pepper fruit color has important practical significance for the development of economically efficient strategies of pepper cultivation.

Pepper fruit color can be divided into two categories depending on the developmental stage of the plant: immature and mature (Wahyuni et al. 2011). Most immature fruits are green because of the accumulation of chlorophyll in their chloroplasts (Paran et al. 2007). Nevertheless, many other pigments, such as lutein, $\beta$-carotene, violaxanthin, and anthocyanins, have been found in immature fruits, leading to fruit colors such as milky yellow, yellowish green, purple, and purplish black (Matsufuji et al. 2007; Lightbourn et al. 2008; Liu et al. 2020). As the fruit ripens, the chlorophyll gradually is degraded, and the chloroplasts are converted into chromoplasts in which carotenoids are synthesized and stored; this process results in orange, red, and yellow mature pepper fruits (Bouvier et al. 1994; Hugueney et al. 1996; Sun et al. 2018; Jeong et al. 2020; Lee et al. 2020). 
Previous studies have shown that the genetics of white, yellowish-green, and deep green immature pepper fruit color is mainly controlled by the $S W 1, S W 2$, and $S W 3$ loci, respectively. SW3 is dominant relative to SW1 and SW2, while SW2 is dominant relative to SW1 (Lightbourn et al. 2008; Stommel et al. 2014). The dominance of these loci indicates that there are genetic differences among the different colors of immature pepper fruits. However, there have been few other studies on immature-fruit color in pepper plants. Brand et al. (2012) found two major quantitative trait loci (QTLs), pc8.1 (also termed pc1, as subsequent mapping placed the QTL in chromosome 1 [Borovsky et al. 2019]) and pc10.1, that control the degree of dark green color saturation in immature fruits based on their chlorophyll content. In 2013, Pan et al. (2013) cloned the APPR2-Like gene in pepper, which positively regulates chlorophyll synthesis in pepper, and found that APPR2-Like and $p c 8.1$ were in the same region on the genetic map, indicating that APPR2-Like may be a candidate gene of pc8.1. However, Borovsky et al. (2019) used bulked segregant analysis (BSA) to find CCLOL 1, a candidate gene of $p c 1$ (pc8.1), and observed that CCLOL 1 affected the formation of green-colored immature fruits by regulating the expression of genes related to photosynthesis and redox reactions. Brand et al. (2014) found that a possible candidate gene of $p c 10.1$ is CaGLK2. In addition, two genes (MybA and Ca3GT) were found to regulate anthocyanin accumulation in purple immature pepper fruits (Borovsky et al. 2004; Liu et al. 2020).

The molecular mechanism underlying the formation of green-colored immature pepper fruits is complex. The sequence analysis of the CaGLK2 open reading frame (ORF) in light-green immature pepper fruits showed that six base insertions, one A-G substitution, and three base deletions occurred at three different positions of its third exon, indicating that there was diversity in the variation of CaGLK2. However, there was no variation in CaGLK2 ORF in "1901", "21 - 1", "Nayoi", and "1202" pepper accessions, which were light-green immature fruits, indicating that CaGLK2 may be down-regulated or that other genes are regulating the formation of immature-fruit color in these accessions (Brand et al. 2014). Borovsky et al. (2019) found that there was no difference in the ORF sequence of CCLOL 1 between C.annuum and C.annuum var glabriusculum, which have significant differences in chlorophyll content, indicating that CCLOL 1 has a limited ability to regulate immature-fruit color variation in pepper plants.

Although some studies have isolated genes related to the color of immature pepper fruits (Borovsky et al. 2004; Pan et al. 2013; Brand et al. 2014; Borovsky et al. 2019; Liu et al. 2020), only a few have reported specifically on the regulatory genes of light-green immature fruits. Among all pepper cultivars, there is a large variation in the hue of green-colored immature fruits, ranging from colors characterized by very low chlorophyll content, such as white or milky yellow, to dark green (Mejia et al. 1988; Levy et al. 1995; Hornero-Mendez et al. 2000; Wall et al. 2001). However, it is difficult to distinguish the different depths of green-colored fruits, especially of those that are yellowish green, milky yellow, light green, green, deep green, and dark green. This difficulty poses a challenge for conducting research on green-colored immature pepper fruits. Some studies have investigated pepper fruit color based on the pigment content (Brand et al. 2012; Borovsky et al. 2019). However, this method is tedious and easily affected by the sampling or determination technique. 
Overall, the genetic and regulatory mechanisms of green-colored immature pepper fruits with different depths of saturation are complex, and there have been few studies on the genetic and mapping of the genes controlling light-green immature fruits. Considering this, we analyzed the heredity and formation of light-green immature pepper fruits in the present study with two $C$. annuum accessions, 17C827 (lightgreen immature fruits; red mature fruits) and 17C658 (green immature fruits; yellow mature fruits). Additionally, we utilized a genome-wide association study (GWAS) and BSA to perform gene mapping and functional analysis of the $L G$ locus that controls light-green coloration in immature pepper fruits-the $L G$ locus was identified based on visual and colorimetric analyses of the color phenotype. Finally, a molecular marker closely linked to the $L G$ locus was developed. So this study provides a valuable reference for future studies on and genetic improvement of the color of immature pepper fruits.

\section{Materials And Methods}

\section{Plant materials}

In this study, we used Capsicum annuum accessions 17C827 (light-green immature fruits; red mature fruits) and 17C658 (green immature fruits; yellow mature fruits) to generate $F_{1}$ and $F_{2}$ populations (941 individuals) for mapping the $L G$ locus which controls the light-green color in immature pepper fruits. In addition, 287 pepper accessions (Supplementary Table 1) were also used for the genome-wide association study (GWAS) (Wu et al. 2019). All the above-mentioned materials were provided by the pepper research laboratory in the College of Horticulture, China Agricultural University and were grown in the greenhouses at ShangZhuang experimental station of China Agricultural University (Beijing, China).

\section{Determination of pigment content}

Exocarp and endocarp (including mesocarp) of the immature pepper fruits in each accession were collected and stored at $-80^{\circ} \mathrm{C} .1 .0 \mathrm{~g}$ sample was used for the pigment extraction. $25 \mathrm{~mL}$ of $95 \%$ ethanol was added into a $50 \mathrm{~mL}$ centrifuge tube containing the sample and then the tube was sealed with a sealing film and placed under dark conditions for $36 \mathrm{~h}$ after ultrasonic $\left(100 \mathrm{~W} ; 26^{\circ} \mathrm{C}\right)$ treatment for $1 \mathrm{~h}$ (Zhu et al. 2017; Vendruscolo et al. 2021). When the sample was whitened, the solution was mixed evenly and the supernatant was kept. Measurement was conducted using spectrophotometer under the $470 \mathrm{~nm}$, $649 \mathrm{~nm}$ and $665 \mathrm{~nm}$, respectively(Amorim-Carrilho et al. 2014). Finally, the contents of chlorophyll and carotenoid were calculated using the Aron formula method (Aron et al. 1649).

\section{Chloroplast observation}

The exocarp portion of pepper fruits were cut into a sample strip $(1 \mathrm{~mm} \times 2 \mathrm{~mm} \times 5 \mathrm{~mm})$ and then were immerged into $2.5 \%$ glutaraldehyde fixed solution and later were stored at $4{ }^{\circ} \mathrm{C}$ overnight. The next day, ultra-thin sections were made according to the slice production process of Jeong et al. (2020). Finally, chloroplasts were observed and photographed by JEM-1400 Flash (JEOL, Tokyo, Japan) (120 kV) transmission electron microscope. 


\section{Color measurement of the immature pepper fruit}

The color of immature fruits of the $F_{2}$ individuals as well as the 287 pepper accession was measured and recorded using colorimeter (CHROMAMETESR-400). Chroma (SD) and Shade (SG) were calculated with the formulas described by Yang et al. (2004). For each parameter, the value for each plant were collected from three fruits and for each fruit, the value was the average of three measurements.

\section{Nucleic acid extraction}

Genomic DNA of each plant was isolated from six fresh leaves using the cetyltrimethylammonium bromide (CTAB) method (Lee et al. 2017). DNA concentration and quality were determined by a NanoDrop 2000 spectrophotometer (Thermo Scientific, Waltham, MA, USA). DNA of which the concentration $\geq 20$ $\mathrm{ng} / \mu \mathrm{L}$ and the volume $\geq 30 \mu \mathrm{L}$ was used for sequencing (Wu et al. 2019). Furthermore, 30 individuals carrying light-green immature fruits and 30 individuals carrying green immature fruit were selected from $941 \mathrm{~F}_{2}$ individuals. Equal amounts of DNA from each individual were mixed to generate the green pool and light-green pool for BSA analysis. For each pool, the final concentration was $40 \mathrm{ng} / \mu \mathrm{L}$.

Total RNA was extracted from various tissues. For 17C827 and 17C658, RNA was extracted from stems, leaves, flowers, and three stages ( 9,12 and 20 days after anthesis) of exocarp. For the virus-inoculated 17C827 used for VIGS analysis, RNA was extracted from light-green exocarp and green exocarp of immature fruit. For the control plants used for VIGS analysis, RNA was also extracted from exocarp of immature fruit. Total RNA was extracted using MG RNAzol kit (MGmed, Seoul, South Korea) according to the manufacturer's instructions. Complementary DNA (cDNA) was synthesized from $2 \mu \mathrm{g}$ of RNA using the EasyScript Reverse Transcriptase kit (TransGen, Beijing, China) with oligo (dT) primers. The resulting cDNAs were used for further analyses.

\section{GWAS and BSA analysis}

The genome of 'Zunla-1' (http://peppersequence.genomics.cn/page/species/index.jsp, version 2.0) was selected as the reference genome for an electronic digestion prediction experiment. The genome size of 'Zunla-1' was 3.36 Gb, and GC content was 34.97\% (Cheng et al. 2014). We used the sequencing data of Wu et al. (2019) to perform the genome-wide association study of immature-fruit color (including yellowish white, milky yellow, yellowish green, light green, green, deep green, dark green, purple and purplish black) in the 287 pepper accessions. The detailed methods of GWAS were described in Wu et al. (2019). The BSA analysis was conducted according to Xu et al. (2016).

\section{Genetic analysis, linkage map construction and QTL analysis}

To determine the mode of genetic of fruit color, Chi-squared $\left(\chi^{2}\right)$ analysis was performed to test the phenotypic data for goodness-of-fit to Mendelian segregation ratios. A large number of SSR, InDel, CAPS and dCAPS markers within the candidate interval of $L G$ were screened and seven polymorphic molecular markers were obtained (Supplementary Table 2). Using the phenotype and genotype data from the $941 F_{2}$ 
individuals, the linkage analysis of $L G$ was carried out by using JoinMap4 software, and a genetic linkage map was constructed with Mapmaker/EXP 3.0 command (LOD value $\geq 3.0$ ) (Lander et al. 2009; Lander et al. 1987). In addition, Interval-mapping QTL analyses in the $315 \mathrm{~F}_{2}$ individuals were performed for the $L$ *, a *, b *, SD and SG value of immature fruit with QTL IciMapping 4.0 software (Meng et al. 2015). Significance threshold level (LOD 3.0) for QTL detection was computed by permutation tests with 1,000 iterations at $P<0.01$.

PCR was conducted using a 10- $\mu \mathrm{L}$ system containing $1.0 \mu \mathrm{L}$ DNA template, $0.5 \mu \mathrm{L}$ forward primers, 0.5 $\mu \mathrm{L}$ reverse primers, $5.0 \mu \mathrm{L}$ Taq polymerase mix (Beijing ComWin Biotech Co.,Ltd., Beijing, China), and $3 \mu \mathrm{L}$ $\mathrm{ddH}_{2} \mathrm{O}$. The thermal cycle was: initial denaturation at $94^{\circ} \mathrm{C}$ for $5 \mathrm{~min} ; 35$ cycles of denaturation at $94^{\circ} \mathrm{C}$ for $30 \mathrm{~s}$, annealing at $58^{\circ} \mathrm{C}$ for $35 \mathrm{~s}$, and extension at $72^{\circ} \mathrm{C}$ for $30 \mathrm{~s}$, before a final extension at $72^{\circ} \mathrm{C}$ for 5 min. Hinf $\triangle$ was used to digest the PCR product of dCAP10-1 marker. The digested PCR product was separated by $7 \%$ polyacrylamide gel electrophoresis (Wu et al. 2019).

\section{Gene expression and bioinformation analysis}

Expression of CaPP2C35, GSA, HEMA1, CHLD, CHLH, CAO, CHLG, CRD1, DVR, SGR1, PAO, NYC, RCCR, $P P H$, and $S G R 2$ were measured by real-time PCR and primers were listed in Supplementary Table 2. The samples used for gene expression analysis were the exocarp of fruit and the reference gene was UBI (AY486137.1) gene. Gene relative expression data is calculated by $2^{-\triangle \Delta C T}$ method, with three biological and three technical repeats. Data is means of three biological replicates. RT-PCR, real-time PCR, and sequencing of PCR products were performed as described by Wang et al. (2019). DNAMAN (Lynnon Biosoft, USA) and MEGA7 software were used to analyze the sequence difference or evolution of related genes or proteins (Kumar et al. 2016). SOPMA (https://npsa-prabi.ibcp.fr/cgi-bin/npsa_automat.pl? page=npsa_sopma.html) and I-TASSER (https://zhanglab.ccmb.med.umich.edu/l-TASSER/) software were used to analyze the primary structure, secondary structure and tertiary structure analysis of CaPP2C35 protein (Ballut et al. 2015; Roy et al. 2010; Yang et al. 2015).

\section{Virus-induced gene silencing of CaPP2C35}

To study the function of the CaPP2C35, virus-induced gene silencing (VIGS) was carried out in the 17C827 according to Cheng et al. (2018) with some modifications. A fragment of CaPP2C35 CDS was selected as the target, and primers were designed using Primer 5 software (Supplementary Table 2). The constructs consisting of pTRV1, pTRV2, pTRV2-PDS, pTRV2-CaPP2C35 were transformed into Agrobacterium tumefaciens GV3101, respectively. The transformed Agrobacterium were cultured for $12 \mathrm{~h}$ in Luria-Bertani (LB) medium ( $20 \mu \mathrm{M}$ acetosyringone, $50 \mathrm{mg} \mathrm{L}^{-1}$ kanamycin, $25 \mathrm{mg} \mathrm{L}^{-1}$ Rif and $10 \mathrm{mM}$ MES) and then were harvested and suspended in the MS buffer ( $200 \mu \mathrm{M}$ acetosyringone, $10 \mathrm{mM}$ MES, 10 $\mathrm{mM} \mathrm{MgCl} 2 \mathrm{pH}=5.6)$ to a final $\mathrm{OD}_{600}$ of approximately 1.0. A mixture of cultures containing 1:1 (v/v) of pTRV1 and pTRV2 was used as TRV control, and meanwhile pTRV1 and pTRV2-PDS were used as a reporter, and pTRV1 and pTRV2-CaPP2C35 were used to silence the CaPP2C35. The effect of VIGS was determined according to Cheng et al. (2018). 


\section{Results}

\section{Low chlorophyll content in the exocarp of $17 \mathrm{C827}$ affects light-green immature-fruit formation}

We examined the cross-section of 17C658 (green immature fruits) and 17C827 (light-green immature fruits) immature fruits. As shown in Figure 1a, both 17C827 and 17C658 immature fruits formed a notable division of green coloration at the boundary between the exocarp and mesocarp; the green portion was located on the exocarp side, and the light-green portion was located on the mesocarp side. The degree of green in the 17C658 and 17C827 immature fruits is, therefore, mainly influenced by the exocarp.

Next, the pigment contents in the exocarp and endocarp (including the mesocarp) of the two pepper accessions were compared. We found that chlorophyll content (chlorophyll a [Figure 1b] and chlorophyll b [Figure 1c]) in the exocarp was significantly different between 17C827 and 17C658 fruits, and the content in 17C827 fruits was lower than in 17C658 fruits. However, there was no significant difference in chlorophyll content in the endocarp (including the mesocarp) between 17C827 and 17C658 fruits during the various periods of fruit development (Figure 1b, c). These results showed that low chlorophyll content in the 17C827 fruit exocarp was the main factor influencing the formation of its light-green immature fruits. Furthermore, chlorophyll content (chlorophyll a [Figure 1b] and chlorophyll b [Figure 1c]) in the exocarp and endocarp (including the mesocarp) of the two pepper accessions decreased from day 5 to day 9 , increased from day 9 to day 12, and gradually decreased and eventually stabilized from day 12 to the $\mathrm{M}$ stage. The change in carotenoid content was similar to that in chlorophyll content (Supplementary Figure 1). The results showed that the degree of green in the immature fruits of 17C658 and 17C827 began to stabilize after day 12 . Meanwhile, total chlorophyll content $(0.048-0.382 \mathrm{mg} / \mathrm{g} \cdot \mathrm{FW})$ in both $17 \mathrm{C} 827$ and $17 \mathrm{C} 658$ fruits was markedly higher than their carotenoid content $(0.003-0.047 \mathrm{mg} / \mathrm{g} \cdot \mathrm{FW})$ during the various periods of fruit development (Supplementary Figure 1), which indicates that the formation of green-colored immature pepper fruits is mainly affected by chlorophyll.

\section{Abnormal chloroplast thylakoids in 17C827 exocarp affects light-green immature-fruit formation}

To explore whether light-green immature-fruit formation of 17C827 plants was affected by chloroplasts, we first examined the number of chloroplasts in a single cell and the number of chloroplast grana in a single chloroplast. Regardless of the evaluation day-day 9 or day 20-there were no significant difference in the numbers of chloroplasts and chloroplast grana between 17C827 and 17C658 fruits (Supplementary Figure 2a). We then measured the perimeter and area of the chloroplast cross section in the exocarp and found that there were significant differences between 17C827 and 17C658 fruits (Supplementary Figure 2b, c). The chloroplast cross-section perimeter and area values of 17C827 fruits were higher than those of 17C658 fruits. Meanwhile, we calculated the increments of the chloroplast section perimeter and area from day 9 to day 20, and we found that the increments of these values in 17C827 were also higher than those in 17C658 (Supplementary Figure 2b, c). At day 9, dividing chloroplasts were found in both 17C827 and 17C658 fruits, indicating that both accessions were able to proliferate chloroplasts (Supplementary Figure 3a). At day 20, we also found that the chloroplast grana of 
the mature chloroplasts in the light-green immature fruits of 17C827 were thinner and more scattered than those of 17C658, and there were fewer stroma lamella in 17C827 than in 17C658 (Supplementary Figure $3 b$ ). The above results indicate that the abnormal chloroplast thylakoids in the exocarp of 17C827 affected the formation of light-green immature fruits.

\section{Light-green color of 17C827 immature fruits is controlled by a single dominant locus}

In the present study, $F_{1}$ and $F_{2}$ were constructed from a cross between 17C827 (light-green immature fruits) and 17C658 (green immature fruits). All $F_{1}$ individuals showed a light-green immature-fruit color, which was the same as that of the female parent 17C827 (Figure 2). In contrast, the immature-fruit colors of the $941 \mathrm{~F}_{2}$ individuals were segregated into light green (726 individuals) and green (215 individuals), with a ratio of $3: 1\left(x^{2}=2.32<6.64, \mathrm{df}=1, p=0.01\right)$, which was similar to the separation ratio of red (701 individuals) and yellow (240 individuals) mature fruits. These results indicate that the formation of lightgreen immature-fruit color could be attributed to the genetics of a single dominant locus compared with the formation of green immature-fruit color. Finally, we found that $F_{2}$ could be segregated according to fruit color, light-green immature-fruit and red mature-fruit (534 individuals), light-green immature-fruit and yellow mature-fruit (174 individuals), green immature-fruit and red mature-fruit (167 individuals), and green immature-fruit and yellow mature-fruit (66 individuals) color, which followed the ratio of 9:3:3:1 $\left(\chi^{2}=1.45<11.35, \mathrm{df}=3, p=0.01\right)$. This result suggest that the genetic mechanisms of immature-fruit color (light green and green) and mature fruit color (red and yellow) are relatively independent from each other.

\section{LG locus position revealed by GWAS and BSA}

To efficiently map the $L G$ locus, a GWAS on immature-fruit color, comprising yellowish white, milky yellow, yellowish green, light green, green, deep green, purple, and purplish black, in 287 pepper accessions was conducted (Supplementary Table 1). As shown in Figure 3a, there was a candidate region spanning from $157,194,038$ bp to $190,675,776$ bp on chromosome 10 that was significantly associated with immaturefruit color. Additionally, a GWAS of immature-fruit colors according to lightness $\left(L^{*}\right)$, red and green coordinates $\left(a^{*}\right)$, and yellow and blue coordinates $\left(b^{*}\right)$ of 287 pepper accessions was conducted, and a candidate region was found on chromosome 10 . The candidate region significantly associated with $L^{*}$ spanned from $176,498,851$ bp to $176,669,957$ bp on chromosome 10 , while that associated with a* spanned from $55,687,612 \mathrm{bp}$ to $62,184,580 \mathrm{bp}$, and that associated with $\mathrm{b}^{*}$ spanned from $175,987,065 \mathrm{bp}$ to $186,812,911 \mathrm{bp}$. Therefore, we assumed that the $L G$ locus controlling color in light-green immature fruits was likely to be located in the region spanning from $157,194,038$ bp to $190,675,776$ bp on chromosome 10. In addition, the BSA of the extreme mixed pool based on $\mathrm{F}_{2}$ showed that there was a candidate region from $156,650,000$ bp to $178,330,000$ bp on chromosome 10 that was significantly associated with the light-green color of immature pepper fruits (Figure $3 b$ ). Finally, we selected the intersection of the GWAS candidate region and the BSA candidate region to determine that the $L G$ locus was located in the region spanning from $157,494,038$ bp to $178,330,000$ bp (size: $20.8 \mathrm{Mbp}$ ) on chromosome 10. Seven primer pairs from the above region were used for linkage analysis of 
the $L G$ locus. The results showed that the $L G$ locus was located between the InDel-106 and InDel-109 primers, with a physical distance of $35.07 \mathrm{kbp}$ (from 174,787,932 bp to 174,823,007 bp) (Supplementary Figure 4a). The QTL analysis for the colorimetry indices ( ${ }^{*}, a^{*}, b^{*}$, chroma [SD], and shade [SG]) of the immature-fruit surfaces of $315 \mathrm{~F}_{2}$ individuals showed similar results (Supplementary Figure $4 \mathrm{~b}$ ).

\section{CaPP2C35 is the candidate gene of the $L G$ locus}

Using the JBrowser tool of the Sol Genomics Network (https://solgenomics.net/), we found that there was only one gene, Capana10g001710, located between 174,787,932 bp and 174,823,007 bp on chromosome 10. Sequence analysis revealed a G-A substitution at the $313^{\text {th }}$ base of the Capana10g001710 coding sequence (CDS) in 17C827 (Supplementary Figure 5). Based on this base substitution, a derived cleaved amplified polymorphic sequence (dCAPS) molecular marker, dCAPS10-1, was designed. As shown in Figure 4a, b, dCAPS10-1 had a stable polymorphism between the two parents and was closely linked to $L G(0.2 \mathrm{cM})$. Meanwhile, the QTL analysis of the colorimetry indices $\left(L^{*}, a^{*}, b^{*}\right.$, $S D$, and $S G$ ) of the immature-fruit surfaces of $315 F_{2}$ individuals showed that the QTLs of $L^{*}, a^{*}, b^{*}, S D$, and SG were all located near dCAPS10-1 (Figure 4c). Additionally, the percentage of variation explained (PVE\%) of dCAPS10-1 for L*, a *, b *, SD, and SG was 27.35\%, 21.43\%, 20.42\%, 17.76\%, and $18.14 \%$, respectively. Furthermore, the expression of Capana10g001710 in 17C827 with light-green pools was significantly higher than that of 17C658 with green pools (Figure 4d, e). Finally, we analyzed the structure of the protein encoded by Capana10g001710 and found that a V-I substitution occurred at the $105^{\text {th }}$ amino acid, which was also the last amino acid in the PP2C35 protein domain. This substitution caused the a-helix of the PP2C35 protein to turn into a $\beta$-fold in 17C827 (Supplementary Figure 6). Hence, Capana10g001710 was named CaPP2C35. Evolutionary analysis showed that the PP2C35 proteins belonged to the $\mathrm{C}$ subgroup of the PP2C protein family (Supplementary Figure 7).

\section{Silencing of CaPP2C35 leads to green stripes on the surface of $17 C 827$ immature fruits}

To further explore the role of CaPP2C35, we silenced this gene in 17C827 (light-green immature fruits) via tobacco rattle virus (TRV)-mediated virus-induced gene silencing (VIGS). The immature fruits of 17C827 plants subjected to TRV2-CaPP2C35 silencing continued to have green stripes on their surfaces that were unable to transition into the light-green color of the surface of the fruits (Figure 5). Additionally, chlorophyll contents in the green and light-green exocarps were determined for fruits treated with TRV2CaPP2C35. The results showed that chlorophyll content in the green exocarp was $0.248 \mathrm{mg} / \mathrm{g} \cdot \mathrm{FW}$ and that in the light-green exocarp was $0.095 \mathrm{mg} / \mathrm{g} \cdot \mathrm{FW}$; thus, there was a significant difference between them. In addition, the green and light-green parts of the exocarp of CaPP2C35-silenced fruits were sampled for CaPP2C35 expression analysis. The exocarp of plants subjected to no treatment or TRV2 treatment was used as negative controls, and the exocarp of plants treated with TRV2-PDS was used as a positive control. The results revealed that the expression of CaPP2C35 in the light-green exocarp of fruits treated with TRV2-CaPP2C35 was not significantly different from that of the control treatments (Figure 6a). However, the expression of CaPP2C35 in the green exocarp of fruits treated with TRV2-CaPP2C35 was significantly lower than that in the light-green exocarp of the same fruits. In addition, the tissue-specific 
expression pattern of CaPP2C35 shows that it was specifically and highly expressed in the fruit tissues of 17C827 (Supplementary Figure 8). These results demonstrate that CaPP2C35 plays a role in the formation of light-green immature pepper fruits.

\section{CaPP2C35 forms light-green immature fruits in $17 \mathrm{C} 827$ by affecting the accumulation of chlorophyll in the exocarp}

To investigate the effect of CaPP2C35 down-regulation on the expression of genes involved in chlorophyll metabolism, we analyzed the expression of key chlorophyll metabolism-related genes in the green and light-green portions of the same fruits treated with TRV2-CaPP2C35. As shown in Figure 6b, the expression of the chlorophyll biosynthesis metabolism-related genes-GSA, HEMA1, CHLD, and CAO-in the green portion of the exocarp was significantly higher than that in the light-green portion. However, there was no significant difference in the expression of genes involved in chlorophyll degradation metabolism (Figure 6c). In addition, we analyzed the expression of chlorophyll metabolism-related genes between 17C827 and 17C658 (Supplementary Figure 9). The results showed that there was a significant difference in the expression of chlorophyll biosynthesis metabolism-related genes between 17C827 and $17 C 658$ at day 9 or day 12, including the expression of GSA, HEMA1,CHLD,CHLH, CAO, CHLG, and $C R D 1$, which were expressed at lower levels in 17C827 than in 17C658. Moreover, there was a significant difference in the expression of the chlorophyll degradation metabolism-related genes-SGR1, PAO, $R C C R$, and SGR2-between 17C827 and 17C658 at day 9 or day 12. In addition, the expression of some of them (RCCR and SGR2) was higher in 17C827 than in 17C658 at day 12. Finally, the co-expression analysis of $C a P P 2 C 35$ and the key chlorophyll metabolism-related genes showed that the expression levels of the genes ( $H E M A 1, C H L H, C A O, C R D 1$, and $C H L D$ ) involved in the chlorophyll biosynthetic pathway were negatively associated with that of CaPP2C35. In contrast, the expression level of SGR1, involved in chlorophyll degradation, was negatively correlated to that of CaPP2C35, whereas SGR2 was positively correlated to that of CaPP2C35 (Figure 7 and Supplementary Figure 10). These results indicate that $\mathrm{CaPP} 2 \mathrm{C} 35$ may participate in the formation of light-green immature fruits in $17 \mathrm{C} 827$ by affecting the accumulation of chlorophyll in the exocarp.

\section{Discussion}

In pepper, the common immature-fruit colors are yellowish-white, milky yellow, green, purple, and purplish black. According to the level of color saturation, green-colored immature pepper fruits can be further subdivided into white, yellowish-green, light-green, green, deep-green, and dark-green fruits. Among them, the color of yellowish-green immature fruits is dominant over that of white immature fruits, while the color of deep green immature fruits is dominant over both yellowish-green and white immature fruits (Lightbourn et al. 2008). The color purple in immature fruits is dominant over green in immature fruits (Borovsky et al. 2004; Liu et al. 2020). Thus, it can be inferred that more saturated immature-fruit colors are likely to dominate those that are less saturated. However, in our study, the light-green immature-fruit color exhibited a single dominant locus compared with the green immature-fruit color, this result enriched the genetic theory of immature-fruit color in pepper. Therefore, there are genetic differences associated 
with the color variations between green-colored immature pepper fruits, and these differences are relatively complex.

Considering the complexity of immature-fruit color genetics in green-colored immature fruits, Brand et al. (2012) studied the genetics between dark green and light-green immature fruits based on chlorophyll content and found two related major QTLs ( $p c 8.1$ and $p c 10.1$ ). In the present study, immature-fruit color was identified by using both visual observation and colorimetry. We verified that the QTL positions of $L^{*}$, $a^{*}, b^{*}, S D$, and SG, which were located in the region spanning from $174,787,932$ bp to $174,823,007$ bp on chromosome 10, were consistent with the linkage analysis results of light-green immature fruits $(L G)$ that were identified visually, which showed the reliability of the results. There was only one gene,

Capana10g001710 (also termed CaPP2C35 because it encodes a PP2C35 protein), in this region, and its physical distance from the genes controlling dark green coloration of immature fruits (CaGLK2) and purple coloration (Ca3GT) was 166.45 Mbp and 18.56 Mbp, respectively (Brand et al. 2014; Liu et al. 2020). The expression of CaPP2C35 in 17C827 with light-green pools was significantly higher than that of 17C658 with green pools, which confirmed that CaPP2C35 was the candidate gene for the $L G$ locus. We also found that there is a G-A substitution at the 313th base of the Capana10g001710 coding sequence (CDS) in 17C827, which potentially changes the structure of the PP2C35 protein. This raised the possibility that the light-green phenotype results from the mutation or expression level or both, which will be studied in subsequent research.

We silenced CaPP2C35 in the light-green immature fruits of pepper accession 17C827 to further analyze its function. After CaPP2C35 was down-regulated, the key chlorophyll synthesis metabolism-related genes located in the green portion of the silenced fruits were up-regulated and promoted the synthesis of chlorophyll, deepening the green saturation on the fruit surface. In addition, SGR2, PAO, and RCCR were up-regulated in 17C827, though they were not in 17C658, whereas CaPP2C35 and the chlorophyll synthesis metabolism-related genes (HEMA1, GSA, CHLD,CHLH, CRD1, CAO, and CHLG) were downregulated in 17C827 (Supplementary Fig. 11). We speculate that the up-regulation of CaPP2C35 in 17C827 promoted the degradation and inhibited the synthesis of chlorophyll, thus reducing the accumulation of chlorophyll in 17C827. These results revealed that CaPP2C35 participates in the formation of light-green immature fruits in 17C827 by affecting the accumulation of chlorophyll in the exocarp, which is similar to the mechanisms of APPR2-Like, CaGLK2, and CCLOL1 (Pan et al. 2013; Brand et al. 2014; Borovsky et al. 2019). APPR2-like indirectly regulated the accumulation of chlorophyll content in pepper fruit through the ABA signal pathway (Pan et al. 2013). CaGLK2 affected the accumulation of chlorophyll by adjusting the size of the chloroplast chamber (volume) (Brand et al.2014). CCLOL1 affected the green color formation of immature fruits by regulating chloroplast size and chlorophyll content (Borovsky et al. 2019). In contrast, CaPP2C35 may regulate chloroplast grana lamella stacking and stroma lamella formation, resulting in differences in the thylakoid area in the chloroplasts and affecting the metabolism and accumulation of chlorophyll, similar to the mechanisms underlying the formation of white immature cucumber fruits (Liu et al. 2016). Therefore, our findings shed light on the formation of light-green coloration in immature pepper fruits. The above results indicate that the 
formation of immature pepper fruits with different green color saturation levels is mainly related to the development of chloroplasts or the content of chlorophyll.

In addition, we designed a marker, dCAPS10-1, and tested it using the $F_{2}$ population and 126 pepper accessions (Supplementary Fig. 12a and Supplementary Table 3). Interestingly, the phenotypic matching rates of dCAPS10-1 in $\mathrm{F}_{2}$ and the 126 pepper accessions were $95.92 \%$ and $75.40 \%$, respectively, which was a phenomenon related to the low phenotypic matching rates for a gene marker. Combined with the PVE\% of dCAPS10-1 for L* (27.35\%), a* (21.43\%), b* (20.42\%), SD (17.76\%), and SG (18.14\%). A possible explanation is that CaPP2C35 had a limited ability to regulate the formation of light-green immature pepper fruits, similar to the abilities of CCLOL1 (Borovsky et al. 2019). Meanwhile, we found that there was no G-A substitution at the 828th base of the CaPP2C35 sequence (313th base of the CaPP2C35 CDS) in some light-green pepper accessions, such as 17C632 and 17C965, indicating that CaPP2C35 may be up-regulated or that other genes may participate in the formation of light-green immature fruits in these accessions (Supplementary Fig. 12b). Similar results have been reported in studies on CCS, CaGLK2, and CCLOL 1 (Lefebvre et al. 1998; Brand et al. 2014; Borovsky et al. 2019). Therefore, dCAPS101 can be used to assist the selection of light-green immature pepper fruits at the seeding stage within a certain range.

In the current study, GWAS, BSA, and linkage analysis revealed that the $L G$ locus controlling light-green immature-fruit coloration in pepper was located in the region between 174,787,932 bp and 174,823,007 bp on chromosome 10. Analysis of the CaPP2C35 sequence and its expression confirmed that CaPP2C35 was the candidate gene for $L G$. Silencing of CaPP2C35 in 17C827 resulted in an increase in chlorophyll content in the exocarp and the appearance of green stripes on the surface of the fruits. These findings shed light on the formation of light-green coloration in immature pepper fruits. In subsequent research, we will further study the specific regulatory molecular mechanism of CaPP2C35 to determine whether it indirectly regulates the development of chloroplast thylakoids and the accumulation of chlorophyll through the ABA signal pathway or related transcription factors. Such research will enrich our understanding of the mechanisms involved in immature-fruit color formation in pepper.

\section{Declarations}

Acknowledgements: This research was supported by The National Key Research and Development Program of China (2017YFD0101903), The Construction of Beijing Science and Technology Innovation and Service Capacity in Top Subjects (CEFF-PXM2019-014207-000032), and The Beijing Fruit Vegetables Innovation Team of Modern Agricultural Industry Technology System (BAIC01-2021). We would like to thank Editage (www.editage.cn) for English language editing.

\section{Author contributions}

L.W. contributed to the experiments and writing of the manuscript. H.W. identified the dominance of lightgreen over green color and initiated the study. S.L. contributed to BSA and GWAS experiments. M.L. 
contributed to candidate gene sequencing. J.L. assisted with the qRT-PCR. Y.W. assisted with the analysis of candidate gene mapping. L.S. contributed to TEM analysis. W.Y. revised the manuscript. H.S. supervised the entire process. All authors have read and approved the final manuscript.

\section{Conflict of interest}

The authors declare no competing interests.

\section{Availability of data and material}

The datasets and materials generated during or analysed during the current study are available from the corresponding author on reasonable request.

\section{References}

1. Amorim-Carrilho K. T., Cepeda A., Fente C. and Regal P., 2014. Review of methods for analysis of carotenoids. Trac-Trends in Analytical Chemistry, 56: 49-73.

2. Arnon D. I., 1949. Copper enzymes in isolated chloroplasts-polyphenoloxidase in beta-vulgaris. Plant Physiology, 24(1): 1-15.

3. Ballut L., Violot S., Shivakumaraswamy S., Thota L. P., Sathya M., Kunala J., Dijkstra Bauke W., Terreux R., Haser R., Balaram H. and Aghajari N., 2015. Active site coupling in plasmodium falciparum gmp synthetase is triggered by domain rotation. Nature Communications, 6:8930.

4. Borovsky Y., Oren-Shamir M., Ovadia R., De Jong W. and Paran I., 2004. The a locus that controls anthocyanin accumulation in pepper encodes a MYB transcription factor homologous to anthocyanin2 of petunia. Theoretical and Applied Genetics, 109(1): 23-29.

5. Borovsky Y., Monsonego N., Mohan V., Shabtai S., Kamara I., Faigenboim A., Hill T., Chen S., Stoffel K., Van Deynze A. and Paran I., 2019. The zinc-finger transcription factor CcLOL 1 controls chloroplast development and immature pepper fruit color in Capsicum chinense and its function is conserved in tomato. Plant Journal, 99(1): 41-55.

6. Bouvier F., Hugueney P., Dharlingue A., Kuntz M. and Camara B., 1994. Xanthophyll biosynthesis in chromoplasts-isolation and molecular-cloning of an enzyme catalyzing the conversion of 5,6epoxycarotenoid into ketocarotenoid. Plant Journal, 6(1): 45-54.

7. Brand A., Borovsky Y., Meir S., Rogachev I., Aharoni A. and Paran I., 2012. Pc8.1, a major QTL for pigment content in pepper fruit, is associated with variation in plastid compartment size. Planta, 235(3): 579-588.

8. Brand A., Borovsky Y., Hill T., Rahman Khalis A. A., Bellalou A., Van Deynze A. and Paran I., 2014. CaGLK2 regulates natural variation of chlorophyll content and fruit color in pepper fruit. Theoretical and Applied Genetics, 127(10): 2139-2148.

9. Cheng Q., Wang P., Liu J. Q., Wu L., Zhang Z. P., Li T. T., Gao W. J, Yang W. C., Sun L. and Shen H. L., 2018. Identification of candidate genes underlying genic male-sterile msc-1 locus via genome 
resequencing in Capsicum annuum L. Theoretical and Applied Genetics, 131(9): 1861-1872.

10. Hornero-Mendez D., de Guevara R. G. L. and Minguez-Mosquera M. I., 2000. Carotenoid biosynthesis changes in five red pepper (Capsicum annuum L.) cultivars during ripening. Cultivar selection for breeding. Journal of Agricultural and Food Chemistry, 48(9): 3857-3864.

11. Hugueney P., Bouvier F., Badillo A., Quennemet J., dHarlingue A. and Camara B., 1996. Developmental and stress regulation of gene expression for plastid and cytosolic isoprenoid pathways in pepper fruits. Plant Physiology, 111(2): 619-626.

12. Jang S. J., Jeong H. B., Jung A., Kang M. Y., Kim S., Ha S. H., Kwon J. K. and Kang B. C., 2020. Phytoene synthase 2 can compensate for the absence of $P S Y 1$ in the control of color in capsicum fruit. Journal of Experimental Botany, 71(12): 3417-3427.

13. Jeong H. B., Jang S. J., Kang M. Y., Kim S., Kwon J. K. and Kang B. C., 2020. Candidate gene analysis reveals that the fruit color locus $c 1$ corresponds to PRR2 in pepper (Capsicum frutescens). Frontiers in Plant Science, 11: 399.

14. Kumar S., Stecher G. and Tamura K., 2016. MEGA7: Molecular evolutionary genetics analysis version 7.0 for bigger datasets. Molecular Biology and Evolution, 33(7): 1870-1874.

15. Lander E. S., Green P., Abrahamson J., Barlow A., Daly M. J., Lincoln S. E. and Newberg L. A., 1987. MAPMAKER: An interactive computer package for constructing primary genetic linkage maps of experimental and natural populations. Genomics, 1(2): 174-181.

16. Lander Eric S., Green P., Abrahamson J., Barlow A., Daly Mark J., Lincoln Stephen E. and Newberg Lee A., 2009. MAPMAKER: An interactive computer package for constructing primary genetic linkage maps of experimental and natural populations (vol 1 pg 174, 1987). Genomics, 93(4): 398-398.

17. Lee J. H., An J. T., Siddique Muhammad I., Han K., Choi S., Kwon J. K. and Kang B. C., 2017. Identification and molecular genetic mapping of Chili veinal mottle virus (ChiVMV) resistance genes in pepper (Capsicum annuum). Molecular Breeding, 37(10): 121.

18. Lee S. Y., Jang S. J., Jeong H. B., Lee S. Y., Venkatesh J., Lee J. H., Kwon J. K. and Kang B. C., 2021. A mutation in Zeaxanthin epoxidase contributes to orange coloration and alters carotenoid contents in pepper fruit (Capsicum annuum). Plant Journal. (Online)

19. Lefebvre V., Kuntz M., Camara B. and Palloix A., 1998. The capsanthin-capsorubin synthase gene: A candidate gene for the $y$ locus controlling the red fruit colour in pepper. Plant Molecular Biology, 36(5): 785-789.

20. Levy A., Harel S., Palevitch D., Akiri B., Menagem E. and Kanner J., 1995. Carotenoid-pigments and beta-carotene in paprika fruits (Capsicum spp.) with different genotypes. Journal of Agricultural and Food Chemistry, 43(2): 362-366.

21. Lightbourn Gordon J., Griesbach Robert J., Novotny Janet A., Clevidence Beverly A., Rao David D. and Stommel John R., 2008. Effects of anthocyanin and carotenoid combinations on foliage and immature fruit color of Capsicum annuum L. Journal of Heredity, 99(2): 105-111.

22. Liu H. Q., Jiao J. Q., Liang X. J., Liu J., Meng H. W., Chen S. X., Li Y. H. and Cheng Z. H., 2016. Mapbased cloning, identification and characterization of the $w$ gene controlling white immature fruit 
color in cucumber (Cucumis sativus L.). Theoretical and Applied Genetics, 129(7): 1247-1256.

23. Liu J. Q, Ai X. Y., Wang Y. H, Lu Q. H., Li T., Wu L., Sun L. and Shen H. L., 2020. Fine mapping of the Ca3GT gene controlling anthocyanin biosynthesis in mature unripe fruit of Capsicum annuum $\mathrm{L}$. Theoretical and Applied Genetics, 133(9): 2729-2742.

24. Liu Y. H., Lv J. H., Liu Z. B., Wang J., Yang B. Z., Chen W. C., Ou L. J., Dai X. Z., Zhang Z. Q. and Zou X. $X ., 2020$. Integrative analysis of metabolome and transcriptome reveals the mechanism of color formation in pepper fruit (Capsicum annuum L.). Food Chemistry, 306: 125629.

25. Matsufuji H., Ishikawa K., Nunomura O., Chino M. and Takeda M., 2007. Anti-oxidant content of different coloured sweet peppers, white, green, yellow, orange and red (Capsicum annuum L.). International Journal of Food Science and Technology, 42(12): 1482-1488.

26. Mejia L. A., Hudson E., Demejia E. G. and Vazquez F., 1988. Carotenoid content and vitamin-a activity of some common cultivars of mexican peppers (Capsicum annuum) as determined by HPLC. Journal of Food Science, 53(5): 1448-1451.

27. Meng L., Li H. H., Zhang L. Y. and Wang J. K., 2015. QTL icimapping: Integrated software for genetic linkage map construction and quantitative trait locus mapping in biparental populations. Crop Journal, 3(3): 269-283.

28. Pan Y., Bradley G., Pyke K., Ball G., Lu C., Fray R., Marshall A., Jayasuta S., Baxter C., van Wijk R., Boyden L., Cade R., Chapman Natalie H., Fraser Paul D., Hodgman C. and Seymour Graham B., 2013. Network inference analysis identifies an APPR2-like gene linked to pigment accumulation in tomato and pepper fruits. Plant Physiology, 161(3): 1476-1485.

29. Paran I. and van der Knaap E., 2007. Genetic and molecular regulation of fruit and plant domestication traits in tomato and pepper. Journal of Experimental Botany, 58(14): 3841-3852.

30. Qin C., Yu C. S., Shen Y. O., Fang X. D., Chen L., Min J. M., Cheng J. W., Zhao S. C., Xu M., Luo Y., Yang Y. L., Wu Z. M, Mao L. K., Wu H. Y., Ling-Hu C. Y., Zhou H. K., Lin H. J., Gonzalez-Morales S., TrejoSaavedra Diana L., Tian H., Tang X., Zhao M. J., Huang Z. Y., Zhou A. W, Yao X. M., Cui J. J., Li W. Q., Chen Z., Feng Y. Q., Niu Y. C., Bi S. M., Yang X. W., Li W. P., Cai H. M., Luo X. R., Montes-Hernandez S., Leyva-Gonzalez Marco A., Xiong Z. Q., He X. J., Bai L. J., Tan S., Tang X. Q., Liu D., Liu J. W., Zhang S. X., Chen M. S., Zhang L., Zhang L., Zhang Y. C., Liao W. Q., Zhang Y., Wang M., Lv X. D., Wen B., Liu H. J., Luan H. M., Zhang Y. G., Yang S., Wang X. D., Xu J. H., Li X. Q., Li S. C., Wang J. Y., Palloix A., Bosland Paul W., Li Y. R., Krogh A., Rivera-Bustamante Rafael F., Herrera-Estrella L., Yin Y., Yu J. P., Hu K. L. and Zhang Z. M., 2014. Whole-genome sequencing of cultivated and wild peppers provides insights into Capsicum domestication and specialization. Proceedings of the National Academy of Sciences of the United States of America, 111(14): 5135-5140.

31. Roy A., Kucukural A. and Zhang Y., 2010. I-TASSER: A unified platform for automated protein structure and function prediction. Nature Protocols, 5(4): 725-738.

32. Siddique Muhammad I., Wai Khin P. P., Mo H. S., Yoo H. J., Jang K. S., Jeon S. G., Hwang J. E. and Kim B. S., 2017. Resistance to phytophthora capsici, restorer-of-fertility genotype for cytoplasmic 
male sterility and chemical quality components of breeding lines developed for improvement of subicho, a land race of pepper in yeongyang. Horticultural Science and Technology, 35(6): 758-768.

33. Stommel John R., Pushko M., Haynes Kathleen G. and Whitaker Bruce D., 2014. Differential genetic of pepper (Capsicum annuum) fruit pigments results in black to violet fruit colour. Plant Breeding, 133(6): 788-793.

34. Sun T. H., Yuan H., Cao H. B., Yazdani M., Tadmor Y. and Li L., 2018. Carotenoid metabolism in plants: The role of plastids. Molecular Plant, 11(1): 58-74.

35. Vendruscolo Raquel G., Fernandes Andressa S., Fagundes Mariane B., Zepka Leila Q., de Menezes Cristiano R., Jacob-Lopes E. and Wagner R., 2021. Development of a new method for simultaneous extraction of chlorophylls and carotenoids from microalgal biomass. Journal of Applied Phycology. (Online)

36. Wahyuni Y., Ballester A. R., Sudarmonowati E., Bino Raoul J. and Bovy Arnaud G., 2011. Metabolite biodiversity in pepper (Capsicum) fruits of thirty-two diverse accessions: Variation in health-related compounds and implications for breeding. Phytochemistry, 72(11-12): 1358-1370.

37. Wall M. M., Waddell C. A. and Bosland P. W., 2001. Variation in beta-carotene and total carotenoid content in fruits of Capsicum. Hortscience, 36(4): 746-749.

38. Wu L., Wang P., Wang Y. H., Cheng Q., Lu Q. H., Liu J. Q, Li T., Ai Y. X., Yang W. C., Sun L. and Shen H. L., 2019. Genome-wide correlation of 36 agronomic traits in the 287 pepper (capsicum) accessions obtained from the slaf-seq-based gwas. International Journal of Molecular Sciences, 20(22): 5627.

39. Xu X. M., Chao J., Cheng X. L., Wang R., Sun B. J., Wang H. M., Luo S. B., Xu X. W., Wu T. Q. and Li Y., 2016. Mapping of a novel race specific resistance gene to phytophthora root rot of pepper (Capsicum annuum) using bulked segregant analysis combined with specific length amplified fragment sequencing strategy. PLoS One, 11(3): e0151401.

40. Yang J. Y., Yan R. X., Roy A., Xu D., Poisson J. and Zhang Y., 2015. The I-TASSER suite: Protein structure and function prediction. Nature Methods, 12(1): 7-8.

41. Yang W. C., Bai X. D., Kabelka E., Eaton C., Kamoun S., van der Knaap E. and Francis D., 2004. Discovery of single nucleotide polymorphisms in lycopersicon esculentum by computer aided analysis of expressed sequence tags. Molecular Breeding, 14(1): 21-34.

42. Zhu Z. Z., Wu Q., Di X. H., Li S. Y., Barba Francisco J., Koubaa M., Roohinejad S., Xiong X. G. and He J. R., 2017. Multistage recovery process of seaweed pigments: Investigation of ultrasound assisted extraction and ultra-filtration performances. Food and Bioproducts Processing, 104: 40-47.

\section{Figures}


a
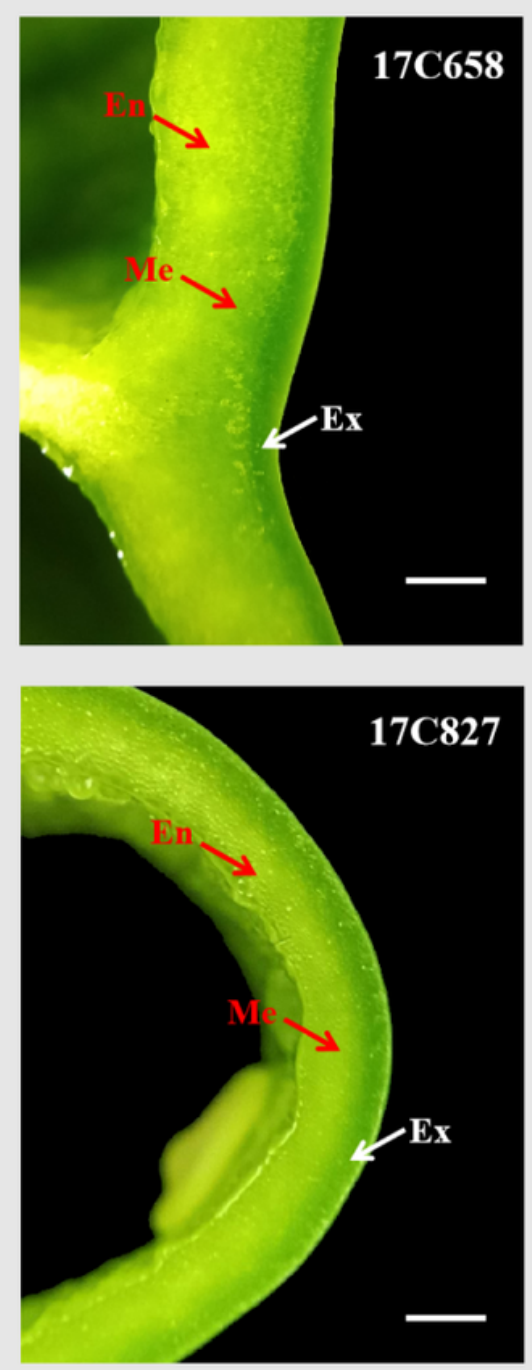

b

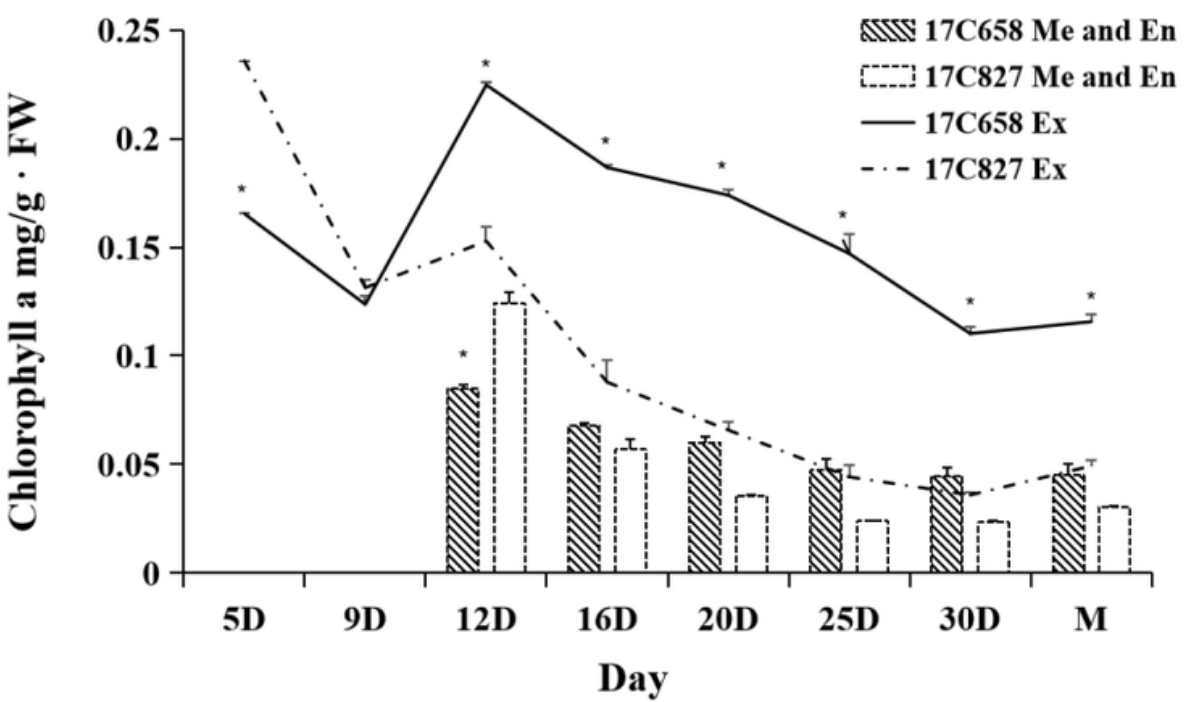

c

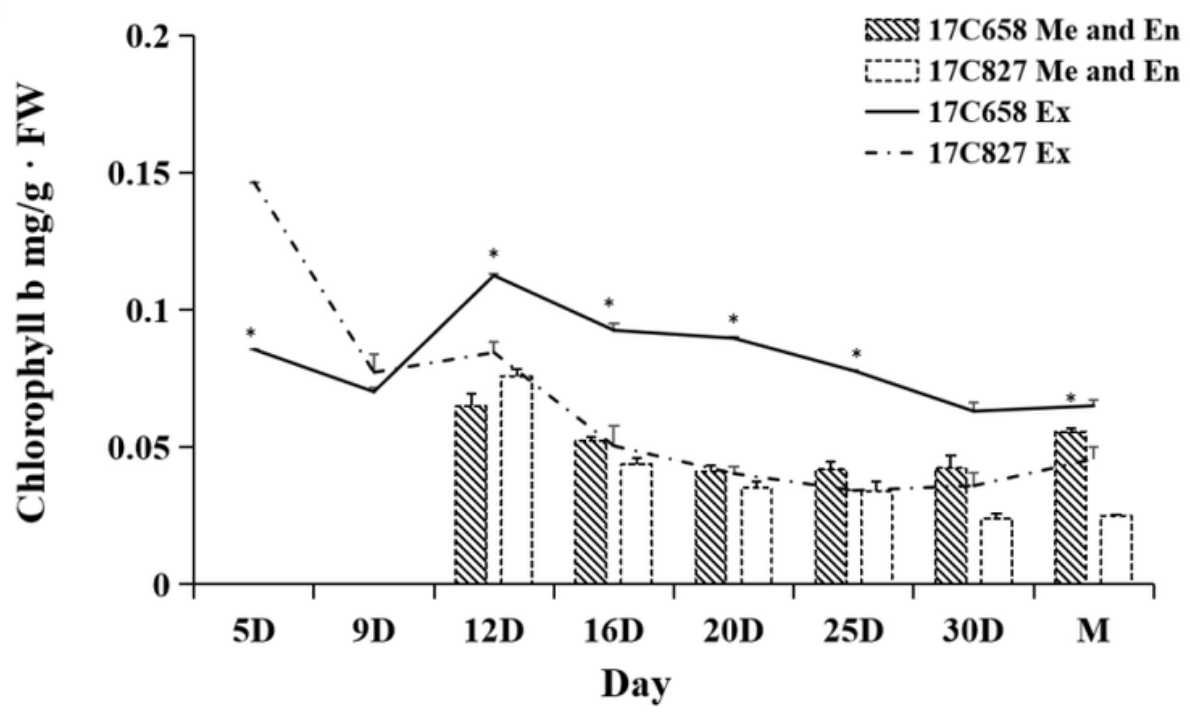

Figure 1

We examined the cross-section of 17C658 (green immature fruits) and 17C827 (light-green immature fruits) immature fruits 


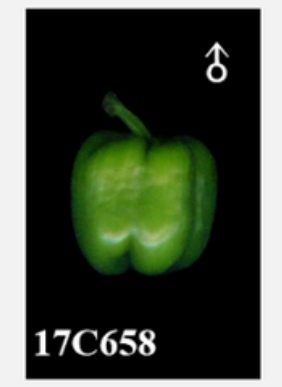

$17 \mathrm{C827}$
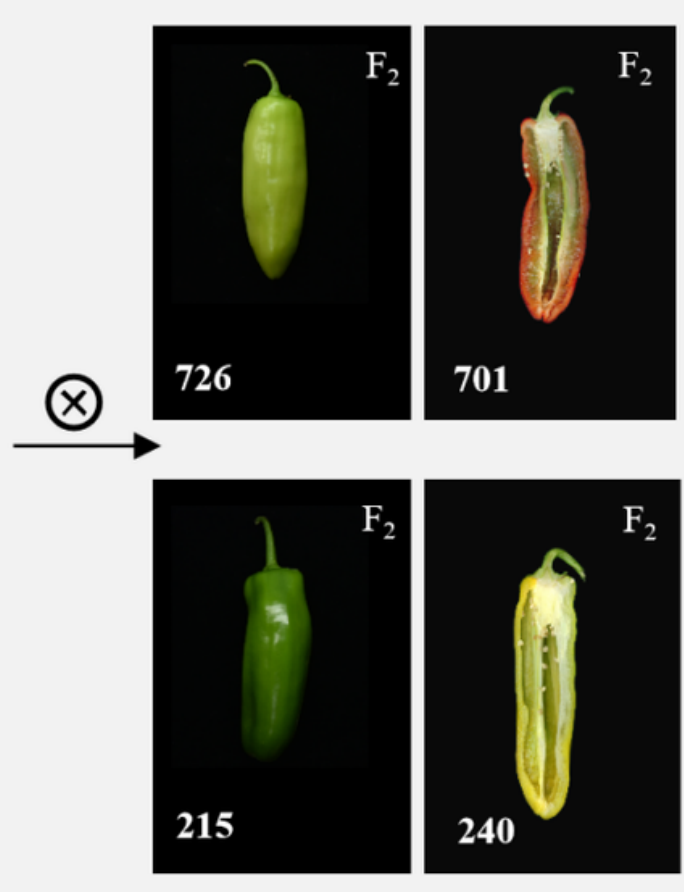

\section{$F_{2} 941$ individuals}

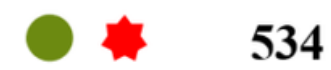

is 174

167

in 66

O: Immature is: Mature

Figure 2

In the present study, F1 and F2 were constructed from a cross between 17C827 (light-green immature fruits) and 17C658 (green immature fruits). All F1 individuals showed a light-green immature-fruit color, which was the same as that of the female parent 17 C827 
a

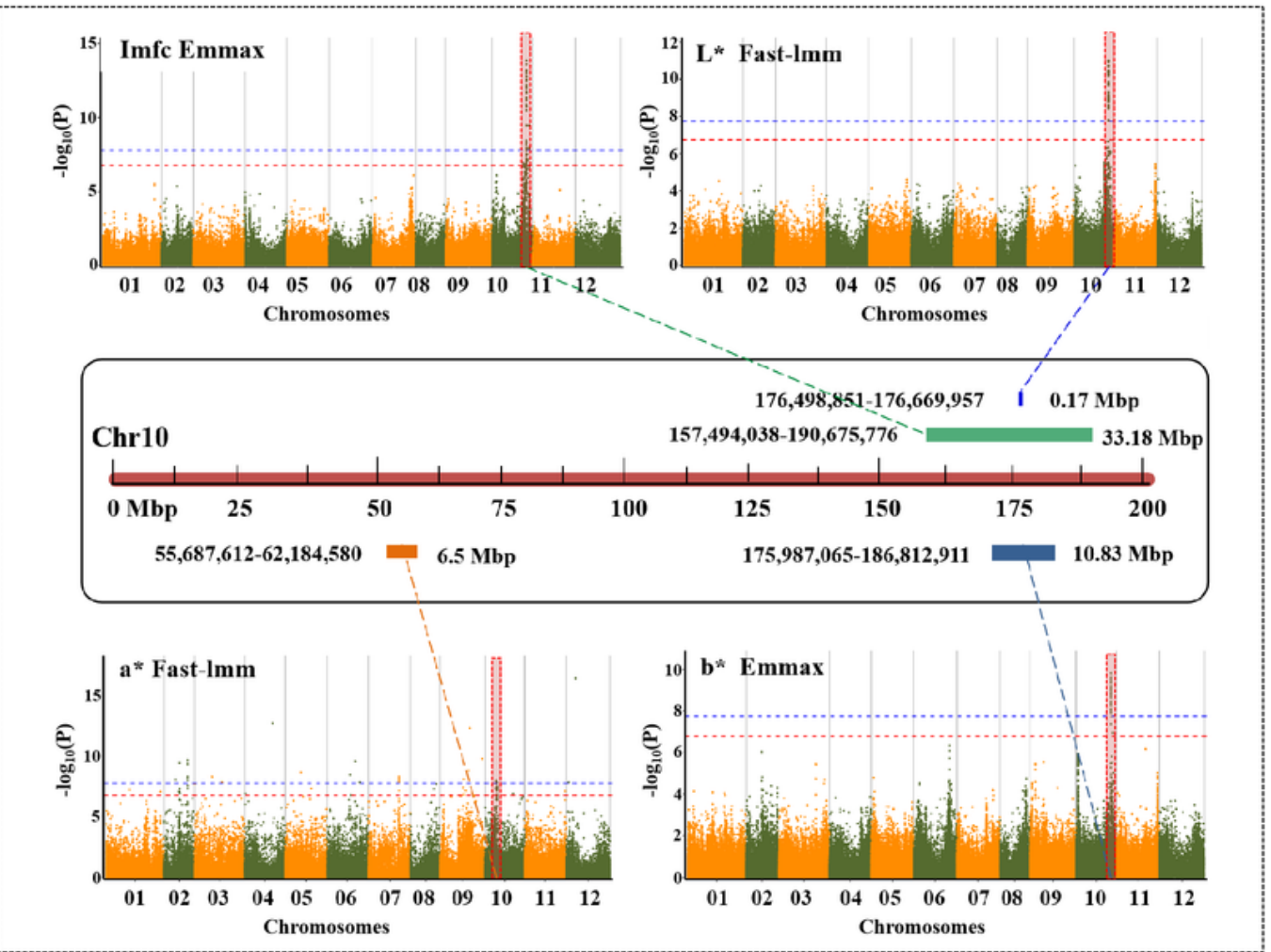

b

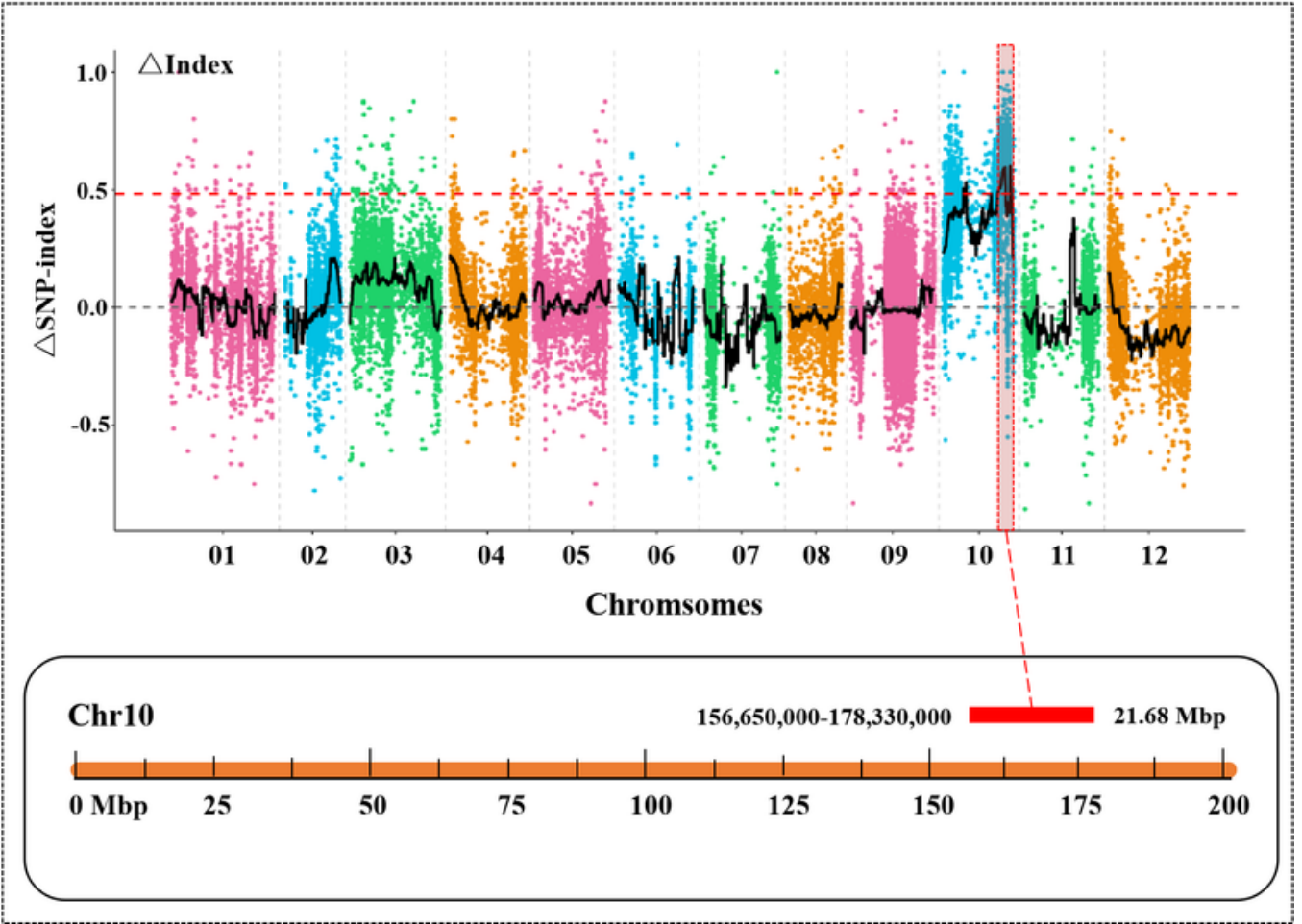

Figure 3

To efficiently map the LG locus, a GWAS on immature-fruit color, comprising yellowish white, milky yellow, yellowish green, light green, green, deep green, purple, and purplish black, in 287 pepper accessions was conducted 


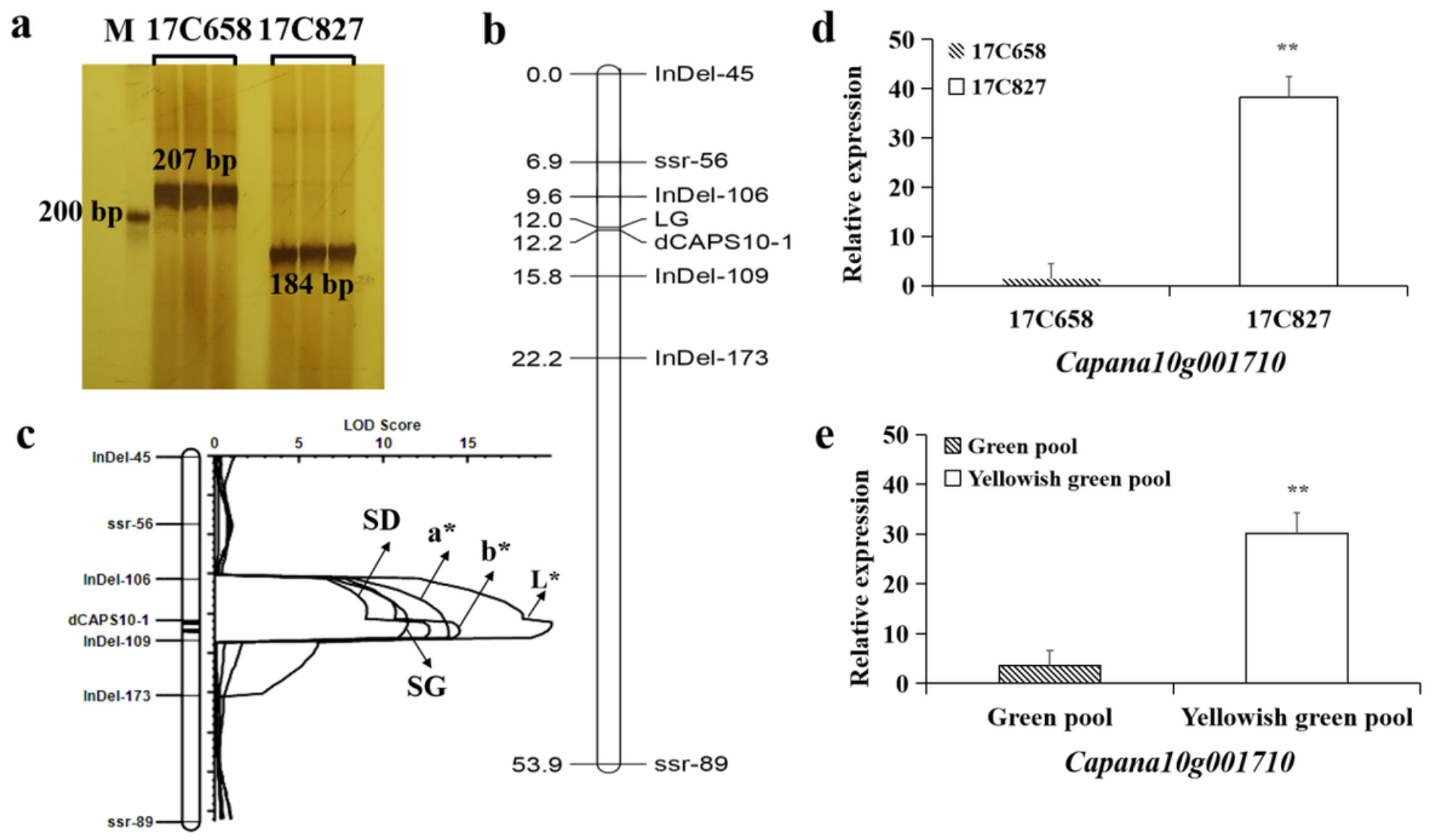

Figure 4

a derived cleaved amplified polymorphic sequence (dCAPS) molecular marker, dCAPS10-1, was designed 

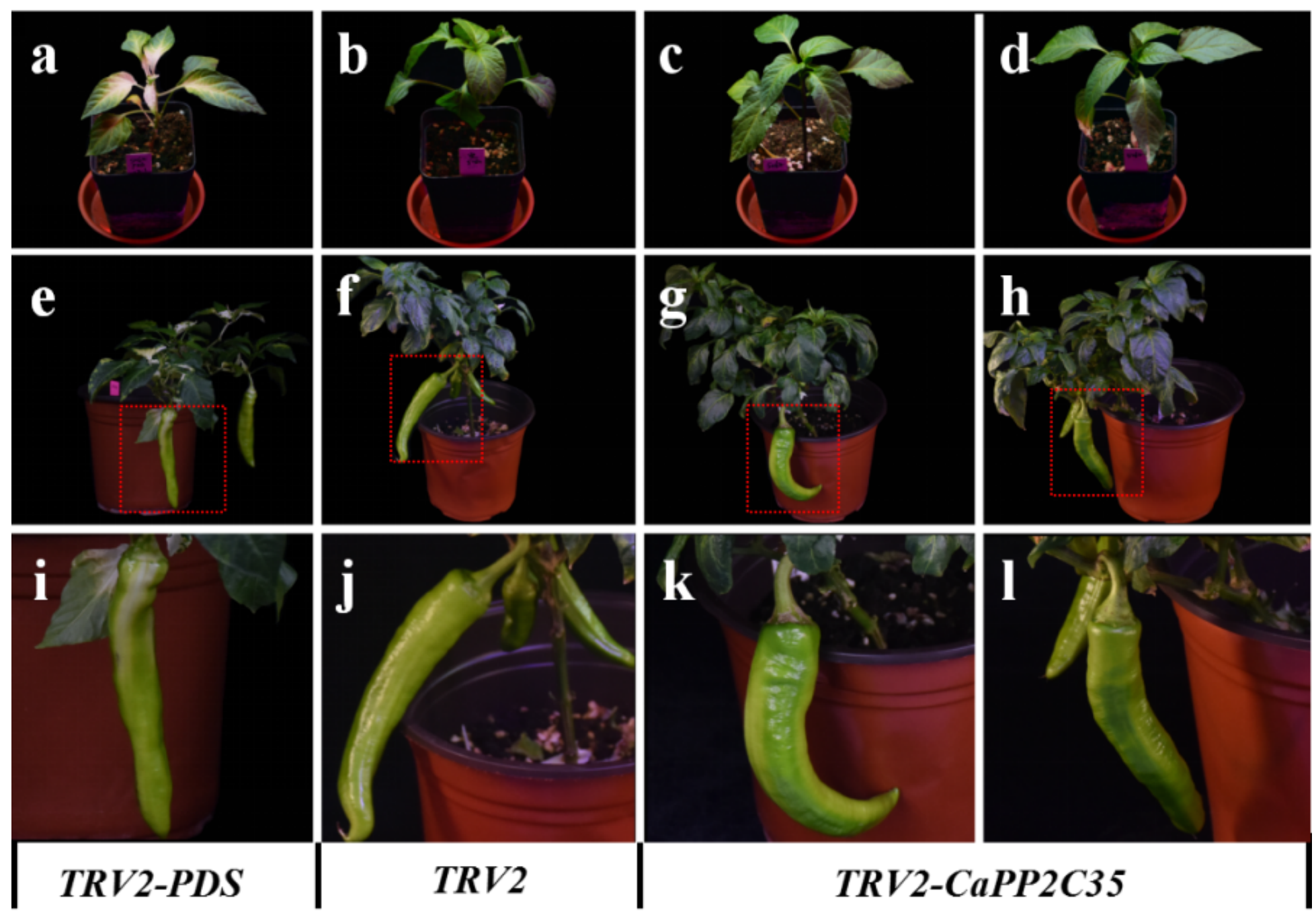

TRV2-PDS

TRV 2

\section{TRV2-CaPP2C35}

\section{Figure 5}

To further explore the role of CaPP2C35, we silenced this gene in 17C827 (light-green immature fruits) via tobacco rattle virus (TRV)-mediated virus-induced gene silencing (VIGS). The immature fruits of 17C827 plants subjected to TRV2-CaPP2C35 silencing continued to have green stripes on their surfaces that were unable to transition into the light-green color of the surface of the fruits 
a

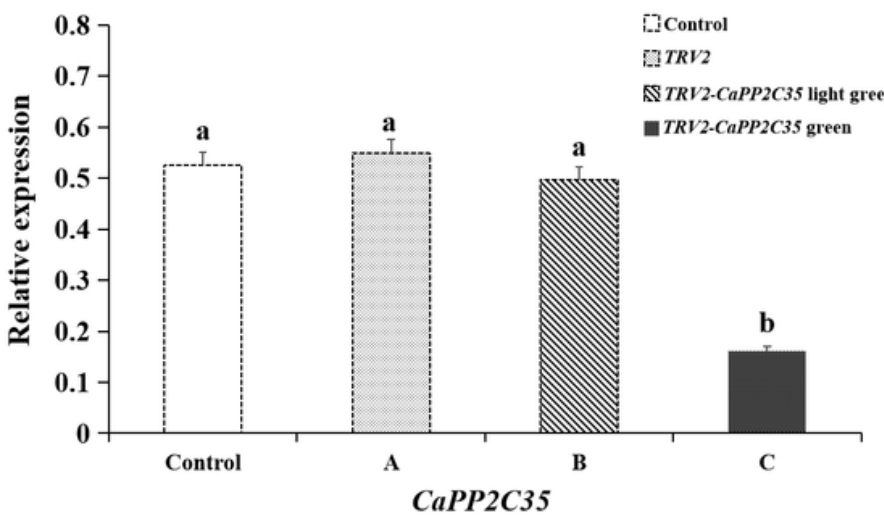

c

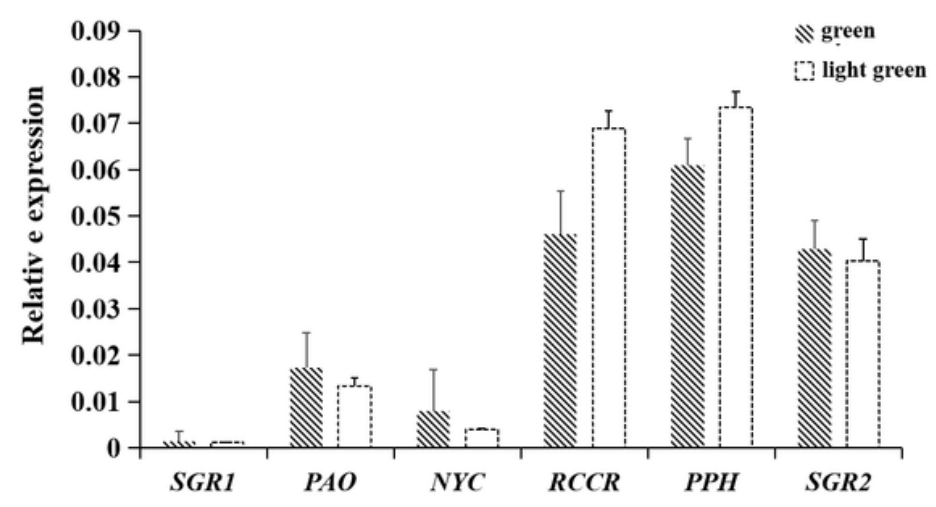

b

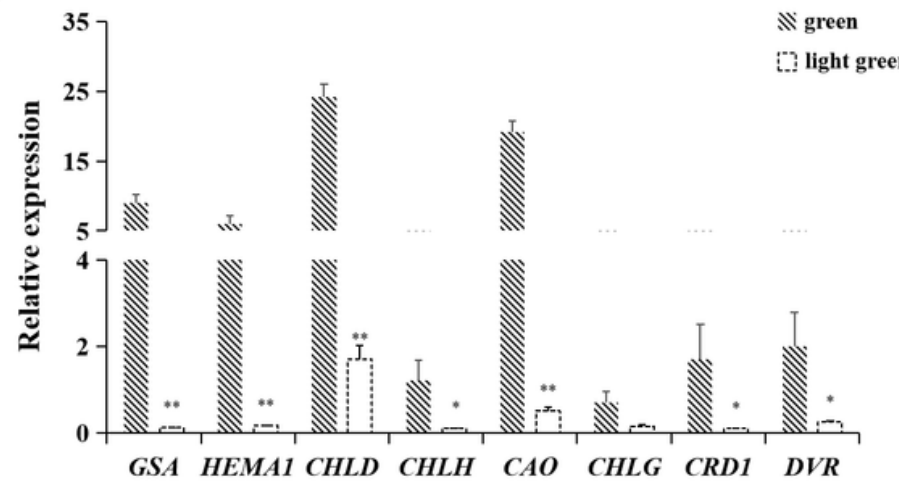

\section{Figure 6}

The results revealed that the expression of CaPP2C35 in the light-green exocarp of fruits treated with TRV2-CaPP2C35 was not significantly different from that of the control treatments 
a

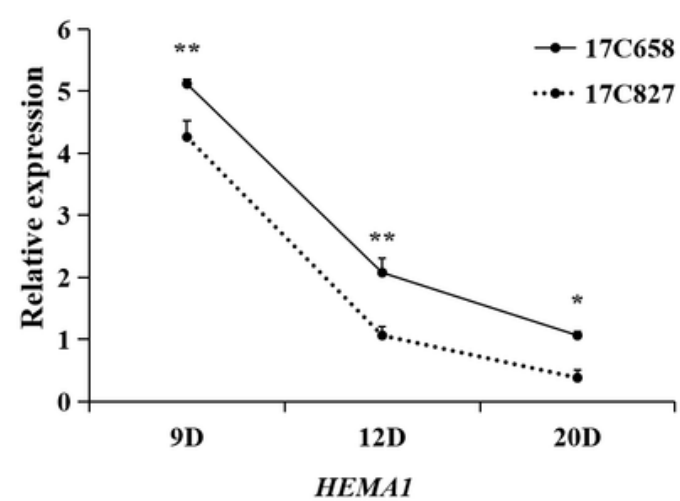

C

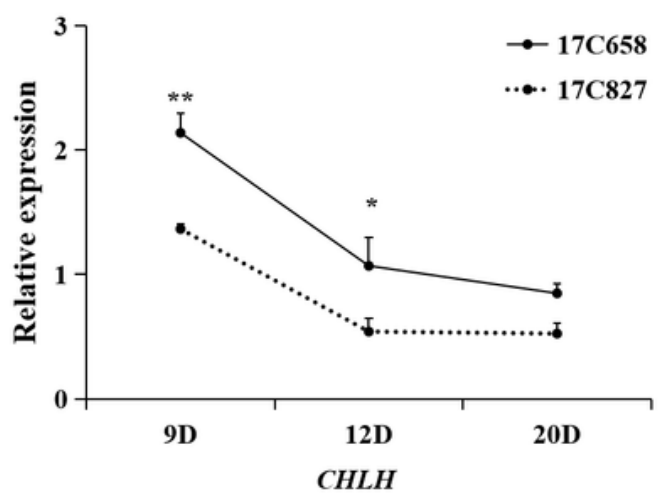

e
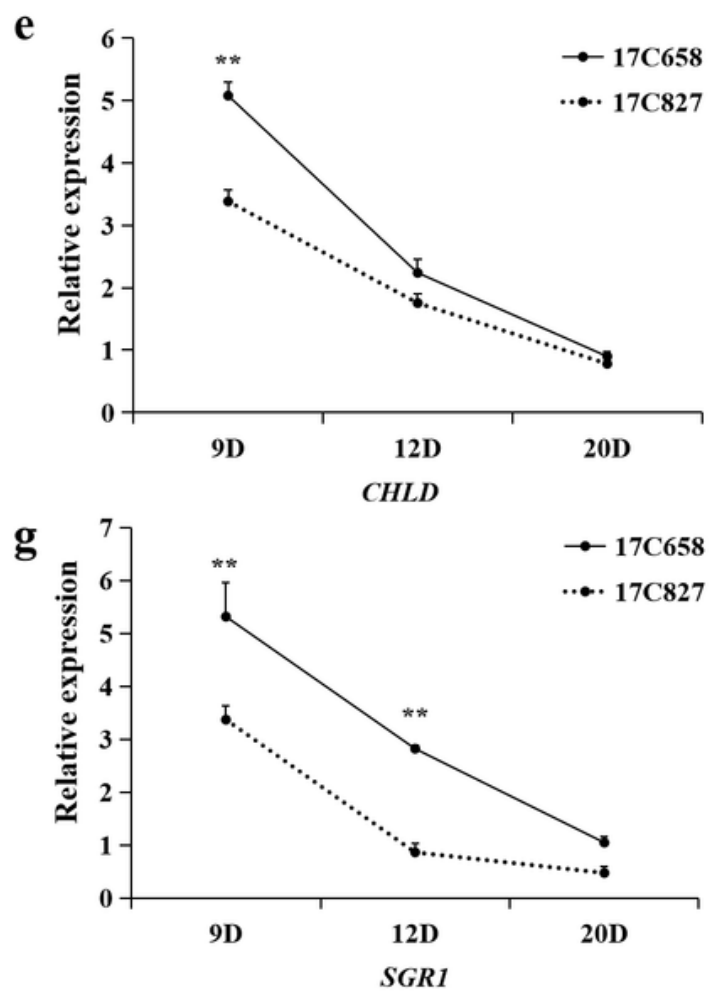

b

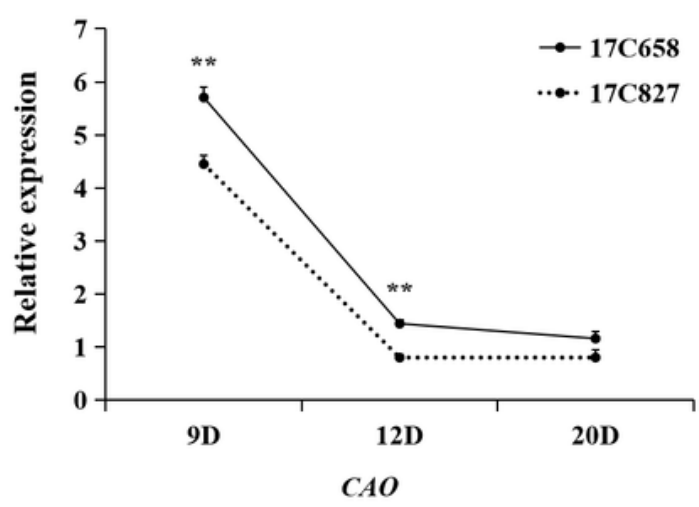

d

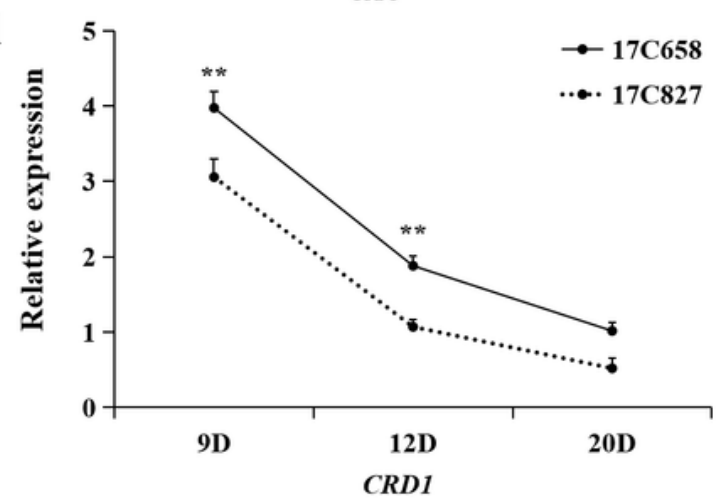

f
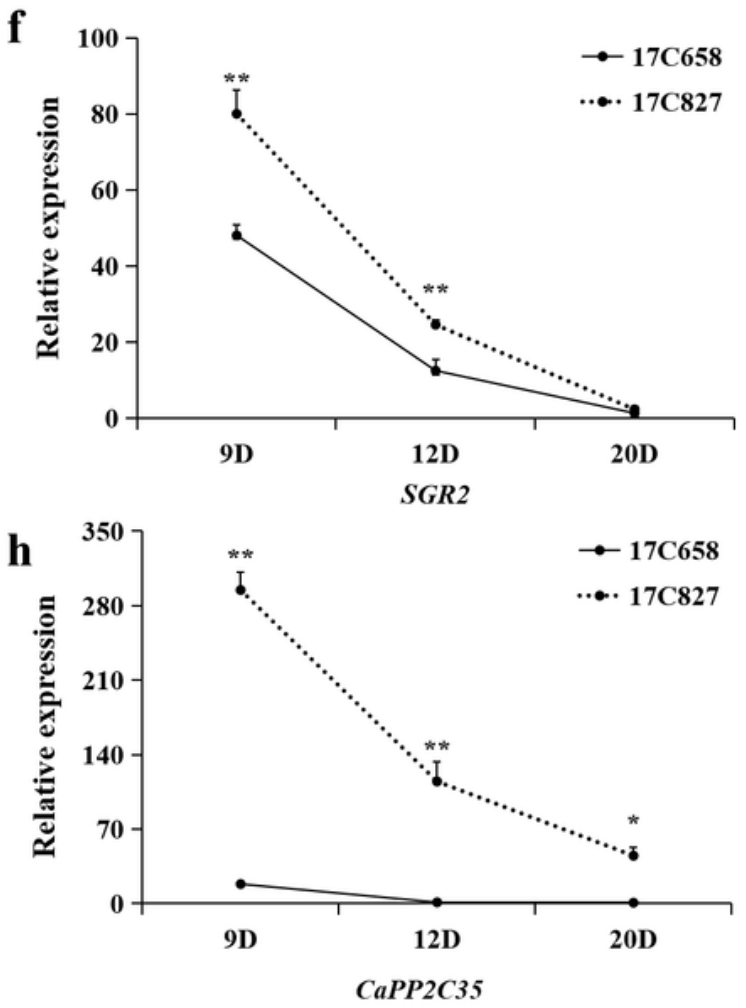

Figure 7

In contrast, the expression level of SGR1, involved in chlorophyll degradation, was negatively correlated to that of CaPP2C35, whereas SGR2 was positively correlated to that of CaPP2C3 
This is a list of supplementary files associated with this preprint. Click to download.

- Supplementarydata.xlsx

- Supplementarytable01.xls

- Supplementarytable02.xlsx

- Supplementarytable03.xIs

- renamedf759b.docx 